\title{
Asymmetric Decarboxylative Allylic Alkylation of Acyclic Enol Carbonates
}

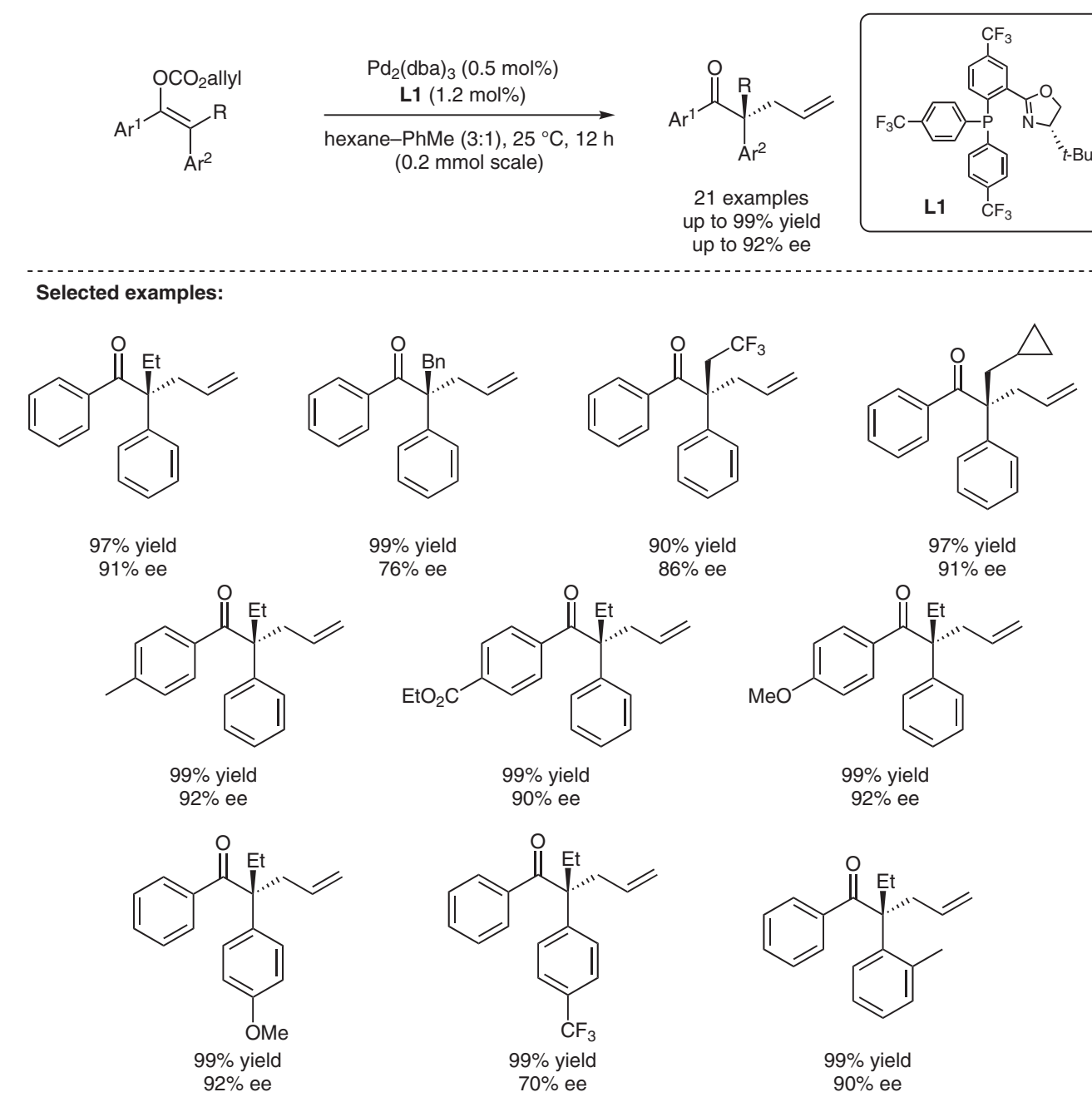

Significance: The authors present the first enantioselective palladium-catalyzed decarboxylative alIylic alkylation of fully substituted non-cyclic enol carbonates. The reaction delivers the linear $\alpha$-quaternary ketones in excellent yields. The phosphinooxazolidine ligand controls the stereoselectivity of the reaction regardless of the $Z / E$ geometry of the enolate starting material.
Category

Metal-Catalyzed Asymmetric

Synthesis and

Stereoselective

Reactions

\section{Key words}

palladium catalysis

decarboxylative allylic alkylation

enol carbonates

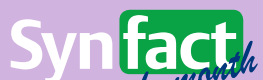
of the

SYNFACTS Contributors: Mark Lautens, Liher Prieto

Synfacts 2018, 14(10), 1041 Published online: 17.09.2018

DOI: 10.1055/s-0037-1610950; Reg-No.: L10618SF

Comment: This work outlines a general method to access linear $\alpha$-quaternary ketones with high enantioselectivity. A dynamic kinetic resolution of the two Z/E geometries of the enolate starting material is postulated under optimal reaction conditions, which comprise the use of an electron-deficient phosphinooxazolidine ligand. 